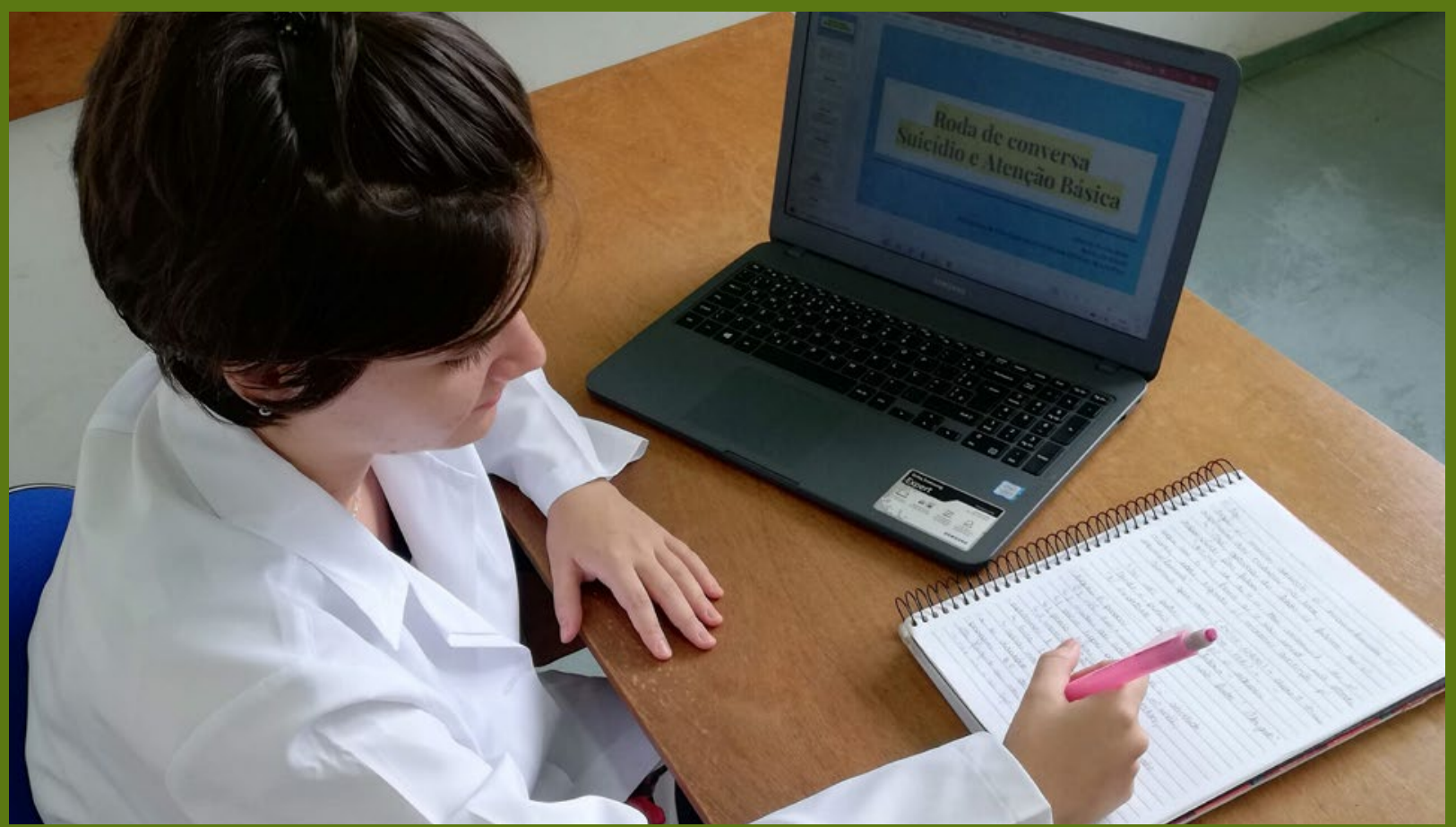

\title{
Análise institucional de práticas psicológicas extensionistas em Unidades Básicas de Saúde
}

\section{Ananda Kenney da Cunha Nascimento' anandakcn@gmail.com}

\section{Sofia Lira Chiodi ${ }^{2}$}

sofialira.s/@gmail.com

1 Doutora em Psicologia clínica (Unicap). Professora colaboradora da Universidade Estadual de Londrina (UEL).

2 Mestranda do programa de pós-graduação em Psicologia e graduada em Psicologia pela UEL. 
RESUMO

Este relato apresenta a experiência de uma prática extensionista, com ênfase em saúde, desenvolvida por um curso de Psicologia de uma universidade pública em um município da região metropolitana de Londrina (PR). Partiu-se da análise institucional, envolvendo observação, identificação de demanda e intervenção. Desenvolveram-se ações extensionistas exitosas com usuários da Atenção Básica e profissionais das equipes de saúde de Únidades Básicas de Saúde.

Palavras-chave: Psicologia. Atenção Básica. Equipe de Saúde. Unidade Básica de Saúde.

ABSTRACT

This report presents the experience of extension practice, with emphasis on health, developed by a Psychology course from a public university in a municipality in the metropolitan region of Londrina-PR. It started from institutional analysis, involving observation, demand identification and intervention. Successful extension actions were developed with Primary Health Care users and health team professionals from Health Centers.

Keywords: Psychology. Primary Health Care. Care Team. Basic Health Unit.

\section{Relato de experiência}

Práticas extensionistas desenvolvidas por uma Instituição de Ensino Superior (IES) reafirmam seu compromisso social para com as necessidades da comunidade em prol da produção de saberes e fazeres e do desenvolvimento social, bem como dos universitários que intervêm na realidade da população (BRASIL, 2007). Assim, este relato apresenta a experiência de uma ação de extensão, com ênfase em saúde, desenvolvida por um curso de Psicologia de uma universidade pública articulada à Secretaria de Saúde de um município da região metropolitana de Londrina (PR) a fim de firmar compromisso com o Sistema Único de Saúde (SUS) no desenvolvimento de ações intersetoriais.

Considera-se o processo longitudinalmente com recorte temporal de três anos letivos - do 3 ao 50 ano de uma universitária de Psicologia -, entre 2017 e 2019, realizada em duas Unidades Básicas de Saúde (UBS), os quais são estabelecimentos da Atenção Básica (AB) que abrangem um "conjunto de ações de saúde individuais, familiares e coletivas que envolvem promoção, prevenção, proteção, diagnóstico, tratamento, reabilitação, redução de danos, cuidados paliativos e vigilância em saúde" (BRASIL, 2017, Art. $2^{\circ}$.

Nesse sentido, esse serviço tem como características principais: longitudinalidade, integralidade e coordenação do cuidado; ou seja, promove atenção continuada ao usuário com o acesso a diferentes ações e intervenções em AB que são ofertadas por uma equipe multiprofissional (PINTO; GIOVANELLA, 2018). Isso implica na responsabilização desse serviço como aquele que deve ser o contato preferencial do usuário com a Rede de Atenção à Saúde (RAS) e assegurar o acesso deste aos outros serviços ofertados pelo SUS. Nesse ínterim, destaca-se que a psicologia se insere na AB por meio do Núcleo Ámpliado de Saúde da Família e Atenção Básica (NASF-AB), que não se constitui como unidade física, atuando em diferentes estabelecimentos no território, entre eles a UBS, contribuindo à integralidade das ações de saúde (BRASIL, 2017).

No processo, adotou-se como procedimento metodológico a análise institucional pautada na intersecção entre campo de pesquisa acerca da produção de demanda a ser trabalhada e o campo da intervenção na saúde. Haja vista que "o campo de intervenção (...) pressupõe um campo de análise, porque se pode entender sem intervir, mas não se pode intervir sem entender, embora durante a intervenção iremos entendendo cada vez mais" (BAREMBLITT, 2002, p. 91).

Fez-se uso da técnica de observação a fim de cartografar o ambiente institucional. Os dados coletados foram registrados em diário de campo (Figura 1) a fim de narrar os acontecimentos com riqueza de detalhes, produzindo um material rico em possibilidades compreensivas de significados e, por conseguinte, interpretações oportunas dos resultados (BARTELMEBS, 2012). 
Figura 1: Diário de campo

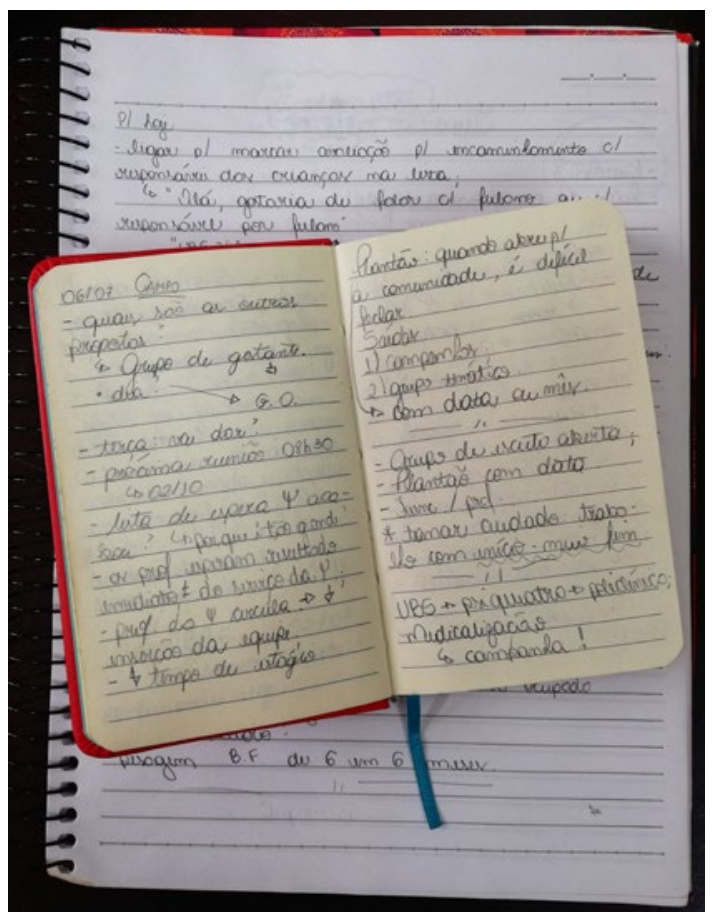

Fonte: Imagem original dos autores.

Periodicamente, realizaram-se reuniões com a gestão da Secretaria Municipal de Saúde e a supervisora da IES, além de reuniões formais e não formais com as equipes das UBS com finalidades de levantamento de demandas no serviço, intervenções conjuntas e avaliação contínua do processo com vistas à manutenção, adequação ou modificação das ações. Considerando, portanto, a dinamicidade da produção de demandas que envolvem conteúdos manifestos (o que é solicitado) e latentes (o que é esperado, inconscientemente, conseguir) (BAREMBLITT, 2002).

De pronto, percebe-se que o lugar, inclusive físico, da psicologia na saúde ainda está sendo conquistado e muitas vezes disputado entre profissionais, pois observou-se que, apesar da enorme lista de espera para triagem psicológica, quando há concorrência entre os profissionais por salas (Figura 2), os médicos têm preferência.

\section{Figura 2: Salas no corredor de uma UBS}

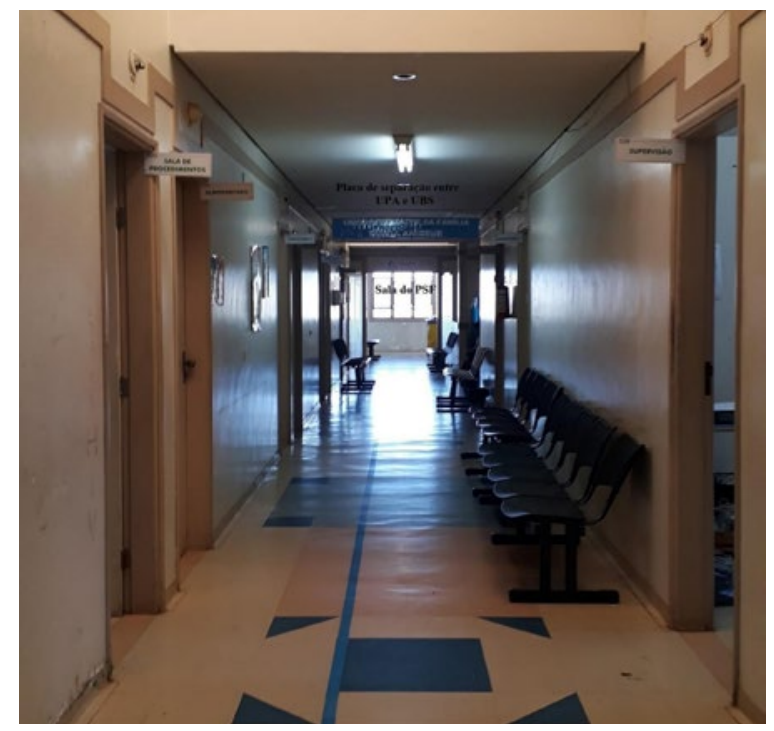

Fonte: Imagem original dos autores. 
Acerca da potencialidade de transformação social na comunidade assistida, destaca-se a contribuição da parceria firmada em um momento crítico de carência de profissionais da psicologia que atuam na $A B$ desse município. Assim, o apoio acadêmico foi imprescindível na resolução de algumas problemáticas que vinham impossibilitando o acolhimento dos usuários que buscam acesso ao serviço, bem como o fluxo de encaminhamentos à RAS e, portanto, a garantia da continuidade do cuidado no SUS.

A exemplo disso, a universitária participou ativamente do planejamento coletivo, da execução individual e/ou conjunta - e da avaliação contínua de intervenções no campo da psicologia em saúde, como pode-se observar na Figura 3. Indo para além da triagem psicológica em consultório, a qual foi o foco das solicitações da gestão e das equipes durante o primeiro ano de prática.

\section{Figura 3: Práticas psicológicas desenvolvidas nas UBSs}

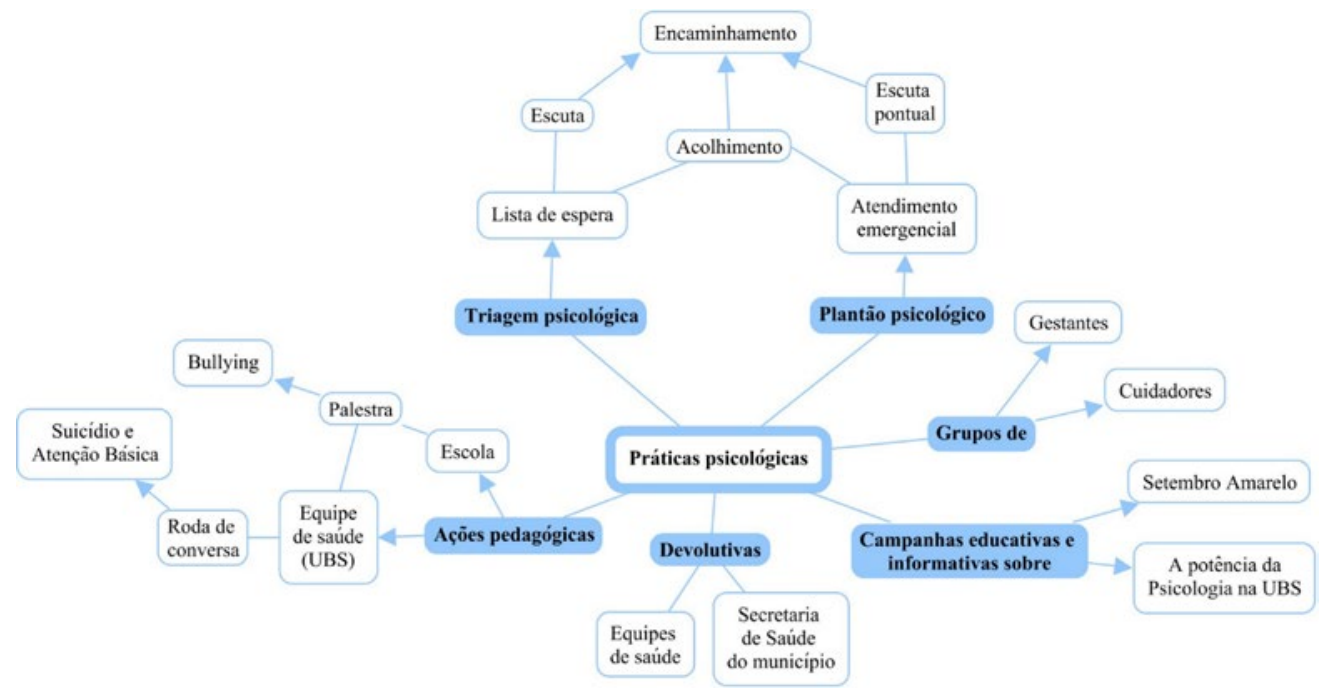

Fonte: Produção original dos autores.

Diante do exposto, reitera-se a importante e necessária parceria entre IES e UBS a fim de atender a uma das diretrizes da Política Nacional de Atenção Básica (PNAB) que é "o acesso universal e contínuo a serviços de saúde de qualidade e resolutivos" (BRASIL, 2017, Cap. 1), favorecendo a garantia do acesso ao SUS pela sua principal e preferencial porta de entrada - UBS - por meio de acolhimento, escuta e oferta de resposta positiva frente às necessidades da população assistida. De igual modo, a universitária entrou em contato com problemas reais e precisou articular-se não só com psicólogos, mas com os demais profissionais da equipe multiprofissional a fim de viabilizar estratégias resolutivas e eficazes, de forma interdisciplinar (Figura 4).

\section{Figura 4: Universitária planejando ação pedagógica}

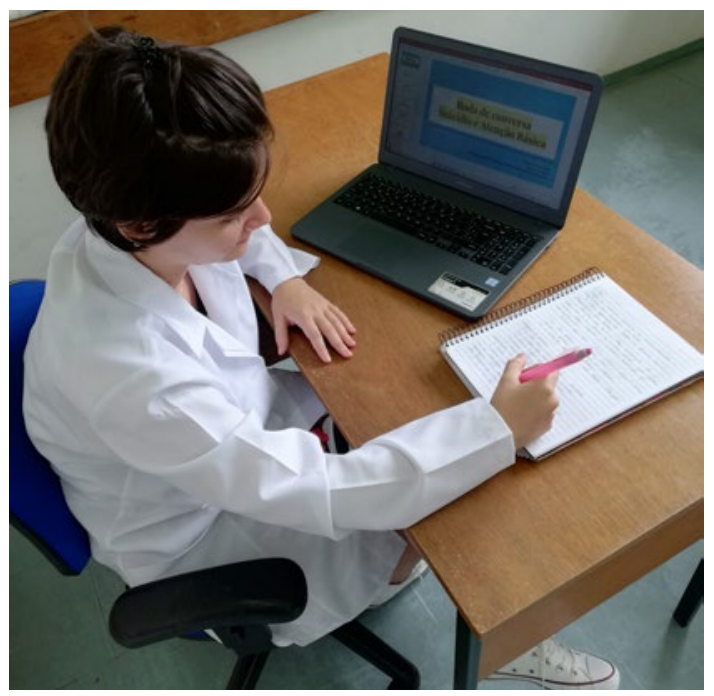

Fonte: Imagem original dos autores. 
Frente a isso, considerou-se que analisar e intervir em uma instituição requer o exercício de um processo dialético que demanda "interação permanente entre observação, compreensão e ação" (BLEGER, 1984, p. 46-47). Por isso, ao longo do processo, foram (re)estabelecidos pactos e vinculação com a gestão e com as equipes de saúde, possibilitando ampliação - não exclusão - de práticas psicológicas.

Nesta trajetória, muitos desafios se apresentaram. Dentre eles destaca-se a dificuldade de engajamento dos usuários ao processo de triagem até o encaminhamento à RAS, devido ao lapso temporal entre procura e atendimento; e o estabelecimento de vínculo com as equipes, seja pela transitoriedade no campo ou pelo modo das equipes operarem. Apesar disso, esta experiência apontou impactos positivos à formação acadêmica, especificamente, no sentido de oportunizar a articulação entre conhecimentos teóricos de políticas públicas em saúde e práticas que possibilitam o desenvolvimento de habilidades e atitudes no fazer da psicologia em saúde com ações voltadas tanto para usuários como para trabalhadores (CONSELHO FEDERAL DE PSICOLOGIA, 2016). Ademais, a universitária pode acompanhar a rotina dos profissionais in loco.

Por fim, acredita-se que a aprendiz desenvolveu um perfil profissional alinhado às demandas reais dos serviços de saúde e habilidades para trabalhar em equipe. Por sua vez, os profissionais demonstraram aprender a nomear e reconhecer as necessidades dos serviços psicológicos para as Unidades; e a comunidade apreendeu, por meio das experiências, possibilidades interventivas psicológicas, o que sinalizou o entendimento da potência da psicologia no campo da saúde.

\section{Referências}

BAREMBLITT, G. F. Compêndio de análise institucional e outras correntes: teoria e prática. 5. ed., Belo Horizonte, MG: Instituto Felix Guattari, 2002.

BARTELMEBS, R. C. A Observação na pesquisa em educação: planejamento e execução. Metodologias de estudos e pesquisas em educação III. Rio Grande: Universidade Federal do Rio Grande - FURG, 2012.

BLEGER, J. Psico-higiene e Psicologia Institucional. Porto Alegre: Artes Médicas, 1984.

BRASIL. Ministério da Educação. Secretaria de Educação Superior. Fórum de Pró-Reitores de Extensão das Universidades Públicas Brasileiras. Extensão universitária: organização e sistematização. Belo Horizonte: COOPMED, 2007.

BRASIL. Ministério da Saúde. Gabinete do Ministro. Portaria n².436, de 21 de setembro de 2017. Aprova a Política Nacional de Atenção Básica, estabelecendo a revisão de diretrizes para a organização da Atenção Básica, no âmbito do Sistema Único de Saúde (SUS). Diário Oficial da União, Brasília, DF, 2017.

CONSELHO FEDERAL DE PSICOLOGIA. Resolução no 3, de 5 de fevereiro de 2016. Altera a Resolução CFP no 013/2007, que institui a Consolidação das Resoluções relativas ao Título Profissional de Especialista em Psicologia e dispõe sobre normas e procedimentos para seu registro. Brasília: CFP, 2016.

PINTO, L. F.; GIOVANELLA, L. Do Programa à Estratégia Saúde da Família: expansão do acesso e redução das internações por condições sensíveis à atenção básica (ICSAB). Ciência \& Saúde Coletiva, Rio de Janeiro, v. 23, n. 6, p. 1903-1914, 2018. 